IFAS Extension

\title{
Vida Saludable: Hiperglicemia e Hipoglicemia ${ }^{1}$
}

Jennifer Hillan²

Si usted padece de la diabetes, de vez en cuando usted puede tener bajos CENAFS los niveles de glucosa (hipoglicemia) o altos los niveles de glucosa en la sangre (hiperglicemia). Ambas condiciones pueden causar serios problemas si no son tratadas. Es importante aprender acerca de la hipoglicemia y la hiperglicemia, así usted puede prevenir y tratar estos síntomas antes de que ellos causen problemas en su salud.

\section{Causas de la Hiperglicemia}

Altos niveles de glucosa en la sangre ocurren cuando el cuerpo no tiene suficiente insulina o cuando el cuerpo no puede utilizar correctamente la insulina. Esto puede ser causado por la sobrealimentación, o por no tomar la dosis suficiente de la medicina diabética, el estrés, o enfermedad.

\section{Síntomas de la Hiperglicemia}

Debido a que altos niveles de glucosa en la sangre pueden aumentar gradualmente, puede ser que usted no note las señales de advertencia. Estas son algunas de las señales que usted puede padecer:

\section{$\checkmark$ Tener más sed}

$\checkmark$ Necesitar ir al baño con más frecuencia

$\checkmark$ Sentir muy cansado o débil

$\checkmark$ Tener la visión borrosa

Su proveedor de la salud fijará un horario para examinar sus niveles de glucosa en la sangre y también le dirá que niveles son demasiado altos.

\section{Tratamiento para la Hiperglicemia}

Hable con su proveedor de salud acerca de la mejor manera de tratar la hiperglicemia. Ellos le pueden ajustar su medicina o su plan de alimentación.

Si usted sufre de diabetes tipo 1, deberá examinar su orina por cetonas, si sus niveles de glucosa en la sangre están más altas de 240 $\mathrm{mg} / \mathrm{dL}$. Pregunte a su proveedor de salud cómo examinar las cetonas en orina.

\section{Prevención de la Hiperglicemia}

Para prevenir los niveles altos de glucosa en la sangre y los problemas de salud asociados con ello, haga lo siguiente,

Sigue su plan de alimentación

$\checkmark$ Toma su medicina según las instrucciones

$\checkmark$ Realice actividad física casi todo los días de la semana.

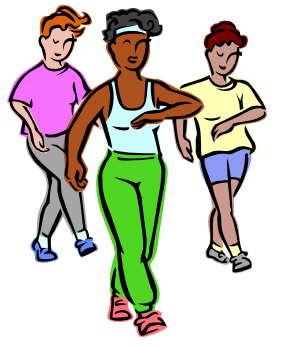

1. The English version of this Spanish document is Healthy Living: Hyperglycemia and Hypoglycemia (FCS8820). Este documento, FCS8820-Span, pertenece a una serie del Departamento de Ciencias de la Familia, Juventud y Comunidad, Servicio de Extensión Cooperativo de la Florida, Instituto de Alimentos y Ciencias Agrícolas, Universidad de la Florida. Fecha de publicación: enero 2007. Favor de visitar el EDIS Web site en el http://edis.ifas.ufl.edu.

2. Jennifer Hillan, MSH, RD, LD/N, ENAFS educadora/entrenadora, Departamento de Ciencias de la Familia, Juventud y Comunidad, Servicio de Extensión Cooperativo de la Florida, Instituto de Alimentos y Ciencias Agrícolas, Universidad de la Florida, Gainesville, FL 32611. Traducción por Jessica R. A. Caicedo, Universidad de la Florida.

El Instituto de Alimentos y Ciencias Agrícolas es un empleador que provee Oportunidades Igualitarias, autorizado a proveer investigación, información educativa y otros servicios, únicamente a los individuos e instituciones que operan sin discriminación alguna con relación al credo, color, religión, edad, incapacidad, sexo, orientación sexual, estado civil, nacionalidad, opinión política o afiliaciones. Para más información sobre como obtener otras publicaciones de extensión, comuníquese con la oficina de Servicio de Extensión de su condado. Servicio de Extensión de la Florida / Instituto de Alimentos y Ciencias Agrícolas / Universidad de la Florida / Larry Arrington, Decano. 
Si usted padece de la diabetes, de vez en cuando puede tener bajos los niveles de glucosa en la sangre, incluso si su diabetes esta bien controlada. Tener bajos los niveles de glucosa en la sangre se llama hipoglicemia y puede también ser llamado una reacción de la insulina. Si la hipoglicemia no es tratada, esta puede provocarle un desmayo.

\section{Causas de la Hipoglicemia}

Bajos niveles de glucosa en la sangre pueden ocurrir si usted pospone una comida, come menos que lo usual, realiza más actividad física que lo usual, o administra

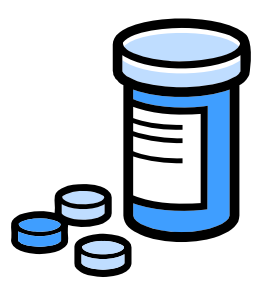
demasiada insulina o demasiadas pastillas.

\section{Síntomas de la Hipoglicemia}

- Temblores

- Mareos

- Sudor

- Piel Pálida

- Hambre

- Dolores de la cabeza

- Confusión

- Movimientos torpes

- Cambios repentinos de comportamiento y temperamento

- Hormigueo alrededor de la boca

- Ataques epilépticos

Su proveedor de salud decidirá con que frecuencia deberá examinar sus niveles de glucosa en la sangre y también le dirá que niveles son demasiado bajos. Examine su nivel de glucosa en la sangre siguiendo su horario y también cuando sienta los síntomas de la hipoglicemia.

Si usted apenas está sintiendo los síntomas, pero no puede hacerse el examen de glucosa, siga el tratamiento para la hipoglicemia.

\section{Tratamiento para la Hipoglicemia}

Trate los niveles bajos en glucosa con azúcar, como por ejemplo:

- 3 pastillas de glucosa

- $1 / 2$ tasa de jugo de fruta o un refresco (no dietético)

- 5 a 6 pedazos de dulces duros

Después del tratamiento, espere de quince a veinte minutos y examine sus niveles de glucosa en la sangre. Si estos permanecen todavía bajos, coma o tome otra porción y espere de quince a veinte minutos para examinar de nuevo sus niveles de glucosa. Si después del tratamiento, los niveles todavía permanecen bajos pida ayuda.

Trate rápidamente la hipoglicemia. Si empeora, usted puede desmayarse. Si esto pasa, necesitará atención médica INMEDIATAMENTE con una inyección de glucagon o visite una sala de emergencias.

Si usted se desmaya, una inyección de glucagon tratará la hipoglicemia. Enseñe a miembros de su familia en como usar el glucagon en el caso de que usted alguna vez lo necesite. Si la inyección no está disponible, llama 911 o visite una sala de emergencias.

\section{Prevención de Hipoglicemia}

Usted puede prevenir los niveles bajos de glucosa siendo consistente con la hora y cantidad de comidas, meriendas y medicina.

$\checkmark$ Nunca posponga sus comidas o meriendas.

$\checkmark$ Intente ingerir día a día la misma cantidad de carbohidratos de comida a comida.

Tome la cantidad correcta de medicina a la hora exacta. 
$\checkmark$ Planee anticipadamente los tiempos cuando usted va a realizar más actividad física que lo usual. Usted puede necesitar ajustar su medicina o comer una merienda adicional.

Siempre mantenga con usted alguna fuente de azúcar en caso de que usted sufra o tenga los síntomas de hipoglicemia.

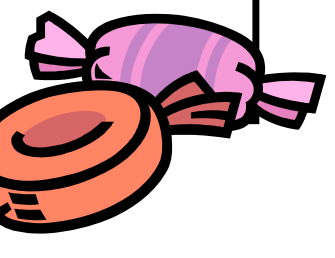

